\title{
Calf Pressure Ulcers: Facts Defying the Prevailing Concept
}

\section{Jochanan E Naschitz ${ }^{1 *}$, Segal Galit ${ }^{2}$, Zaygraykin Natalia ${ }^{3}$, Starikov Natalia $^{3}$ and Leibovitz Gregory ${ }^{4}$}

${ }^{1}$ Professor, Bait Balev Nesher, Department of Geriatric and Palliative Care, and

The Ruth and Bruce Rappaport Faculty of Medicine, Technion, Israel Institute of

Technology, Haifa, Israel

${ }^{2}$ Bait Balev Nesher, Department of Rehabilitation, Israel

${ }^{3}$ Department of Long-Term Mechanical Ventilation, Israel

${ }^{4}$ Department of Geriatric and Palliative Care, Israel

*Corresponding Author: Jochanan E Naschitz, Professor, Bait Balev Nesher,

Department of Geriatric and Palliative Care, and The Ruth and Bruce Rappaport

Faculty of Medicine, Technion, Israel Institute of Technology, Haifa, Israel.
Received: May 21, 2020

Published: July 09, 2020

(C) All rights are reserved by Jochanan $\mathbf{E}$

Naschitz., et al.

\begin{abstract}
Background: According to the classical concept the capillary closing pressure is $30-32 \mathrm{mmHg}$ and the calf interface pressure is 10 - $20 \mathrm{mmHg}$. So, pressure ulcers cannot occur on the calf. Observations from the bedside oppose the concept.

Aim: To examine the features and clinical context of what appear to be calf pressure ulcers.

Design: Prospective observational study in a long-term geriatric and palliative care unit.

Methods: Guideline directed diagnosis and treatment of skin ulcers.

Results: Six out of 1631 patients newly admitted to our institution during a 15 month period had skin ulcers on their calves, resembling typical pressure ulcers. In four patients the calf ulcers evolved concurrently with pressure ulcers at other sites. Two patients had a single calf ulcer and no other pressure ulcer. By the ulcers' location, the clinical context and the normal appearance of the adjacent skin, the calf ulcers differed from venous, ischemic, neuropathic and vasculitic ulcers. Except for their elongated shape, contrasting to the round shape of pressure ulcers at other sites, the calf ulcers were similar to typical pressure ulcers. Calf pressure ulcers have been ignored in the literature, maybe as a consequence of the longtime dominant theory concerning pathophysiology of pressure injury. Recent studies have revised the classical concept, showing that tissue pressures can become critical at levels inferior to conventional capillary closure pressure, depending on systemic influences.

Conclusion: Six case histories provide evidence that calf ulcers may be genuine pressure ulcers and lend support to the contemporary, comprehensive theory of pressure injury.

Keywords: Ulcers; Capillaries; Pressure Injury
\end{abstract}

\section{Introduction}

Pressure injuries represent a localized area of damage to the skin, soft tissue, muscle, or underlying tissues as a result of unrelieved pressure, especially where soft tissues are compressed between a bony prominence and any external surface [1,2]. Decubitus provokes high interstitial pressures which deform and collapse the capillaries $[3,4]$, resulting in ischemia and hypoxia when lasting for a long time, and finally necrosis, i.e. pressure injury. The points of highest tissue pressure with the patient supine are at the sacrum, buttocks, heels and occiput, which are subject to pressures of 50 - $60 \mathrm{mmHg}$ [5]. The average capillary closing pressure, as measured by early investigators, is $30-32 \mathrm{mmHg}$ [5]. Therefore, when the soft tissues at the sacrum, buttocks, heels or occiput are compressed to higher than capillary closure pressure for long peri- 
ods of time, the resulting injury is called 'pressure ulcer', in keeping with tradition [1], or 'pressure injury' using the current definition [2]. Since interface pressures between the calf and the support surface in a supine person is $10-20 \mathrm{mmHg}$ (as measured in the healthy male) and the capillary closure pressure approximates 32 $\mathrm{mmHg}$, calf ulcers do not fit the classical concept of pressure injury.

Calf ulcers are a common finding in practice and are due to various causes: venous insufficiency, vasculitis, metabolic disorders, neoplasia, infection, the effect of medications. On examination, the appearance of these ulcers differs from the appearance of pressure ulcers. Also different are the patients' clinical background and the features of the skin adjacent to the ulcer [6]. In distinction to the latter, several patients referred to our institution in post-acute care had calf ulcers that appeared to be pressure ulcers. The latter emerged in the absence of venous insufficiency, vasculitis, metabolic, or other recognizable causes of calf ulcers. To the clinician, the diagnosis 'calf pressure ulcer' was straightforward. Yet, perusing the literature under the key wards "calf, calves" AND "pressure ulcer, pressure sore, decubitus ulcer, bed sore, pressure injury" we could not find reference to calf pressure ulcers, except a recent reference of ours [7].

\section{Case Histories}

Our 210-bed institution includes facilities for rehabilitation, comprehensive nursing, and palliative care for elderly patients. During the 15 month period February $1^{\text {st }} 2018$ - 30 ${ }^{\text {th }}$ April 2019, there were 1631 new admissions to our institution. Six patients had pressure ulcers on the calves. The patients' pertinent features are shown in table 1 . Brief case histories are presented next.

\begin{tabular}{|c|c|c|c|c|c|c|c|c|c|c|c|c|}
\hline \multirow{2}{*}{ Patient } & \multirow{2}{*}{ Gender } & \multirow{2}{*}{$\begin{array}{c}\text { Age } \\
\text { (Years) }\end{array}$} & \multicolumn{4}{|c|}{ Acute Hospital Care } & \multirow{2}{*}{ IPC } & \multicolumn{5}{|c|}{ Postacute Care } \\
\hline & & & Days & Chief Dx & Sepsis & Shock & & BMI & Sarcop. & Calf PU & Other PU & Healed First \\
\hline Case 1 & $\mathrm{~F}$ & 73 & 61 & Bacterial endocarditis & + & - & & 19.7 & +++ & $1+1$ & $\begin{array}{l}\text { Presacral, } \\
\text { low back }\end{array}$ & Calf PU \\
\hline Case 2 & M & 48 & 92 & Anoxic brain damage & + & CPR & & 18.4 & - & $1+1$ & $\begin{array}{l}\text { Presacral, } \\
\text { chest }\end{array}$ & Calf PU \\
\hline Case 3 & M & 55 & 44 & $\begin{array}{c}\text { Narcotic overdose, coma, } \\
\text { mechanical ventilation, renal } \\
\text { failure }\end{array}$ & + & + & & 24 & - & $1+1$ & $\begin{array}{l}\text { Presacral, } \\
\text { heel, ear }\end{array}$ & $\begin{array}{l}\text { Exitus } 1 \text { days } \\
\text { after admis- } \\
\text { sion }\end{array}$ \\
\hline Case 4 & M & 65 & 83 & $\begin{array}{l}\text { Sepsis, anoxic brain damage, } \\
\text { mechanical ventilation, }\end{array}$ & + & CPR & & & & & $\begin{array}{c}\text { Presacral, } \\
\text { hip, shoulder, } \\
\text { scapula, ear }\end{array}$ & $\begin{array}{l}\text { Exitus } 21 \\
\text { days after } \\
\text { admission }\end{array}$ \\
\hline Case 5 & M & 84 & 29 & $\begin{array}{c}\text { Carcinoma of colon, chronic } \\
\text { atrial fibrillation, antico- } \\
\text { agulant treatment, subdural } \\
\text { hematoma }\end{array}$ & + & - & + & 25 & - & 1 & None & 14 days \\
\hline Case 6 & $\mathrm{~F}$ & 90 & 42 & $\begin{array}{l}\text { Aspiration pneumonia, me- } \\
\text { chanical ventilation }\end{array}$ & + & + & + & 32.6 & ++ & 1 & None & 90 days \\
\hline
\end{tabular}

Table 1: Patient characteristics, diagnosis, risk factors of pressure injury and location of pressure ulcers.

Dx: Diagnosis; IPC: Intermittent Pneumatic Compression; BMI: Body Mass Index; Sarcop: Sarcopenia; PU: Pressure Ulcer.

Case 1

A 73-year-old woman was admitted to our institution for treatment of stage 3 pressure ulcers which developed during a 2-months hospitalization for bacterial endocarditis. Her medical history included numerous hospitalizations for schizoaffective disorder. She had been active and, until recently, able to perform two block walks. When admitted to our department in May 2018 she had completed the prescribed antibiotic regimen. Her body temperature and blood pressure were normal, the body mass in- dex was 20.4. There was severe muscle wasting, most prominent of the calf muscles. A 3/6 pansystolic murmur was perceived at the cardiac apex. There were round, stage 3 pressure ulcers on typical locations: one in the lumbar area adjacent to the L1-L2 vertebrae, $6 \mathrm{~cm}$ in diameter, and three pre-sacral, the largest being $4 \mathrm{~cm}$ in diameter (Figure 1). On each calf there was a partially epithelized skin ulcer, respectively $20 \mathrm{~cm}$ and $22 \mathrm{~cm}$ long (Figure 2). The hemoglobin was $10 \mathrm{~g} / \mathrm{dL}$, the MCV 97, serum albumin $3 \mathrm{~g} / \mathrm{dL}, \mathrm{C}$ reactive 


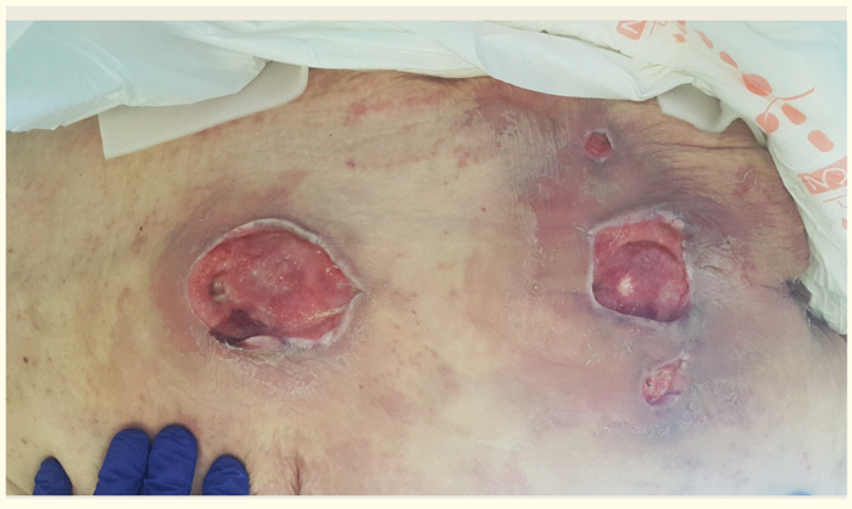

Figure 1: Pressure ulcers at the lower back and presacral area.

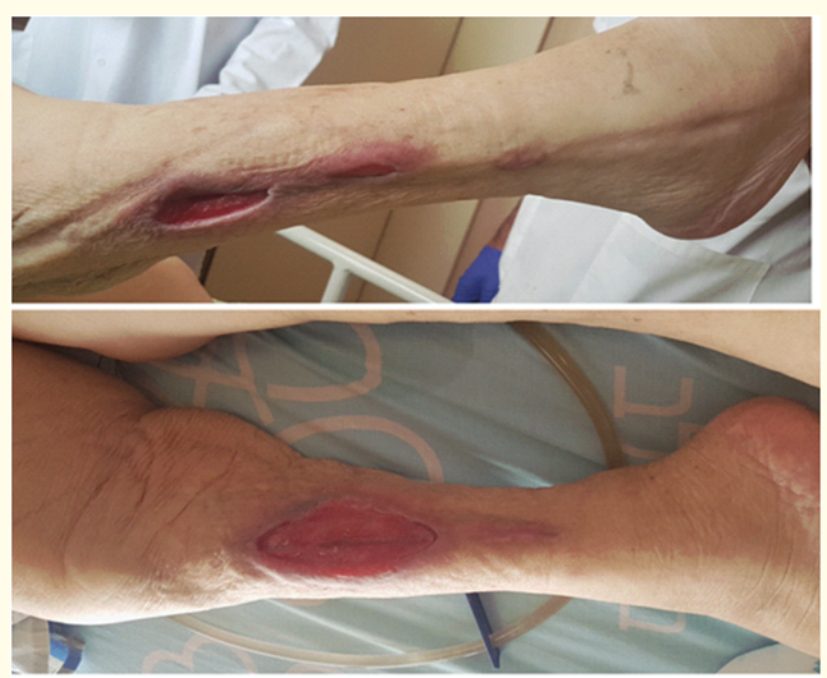

Figure 2: Calf pressure ulcers.

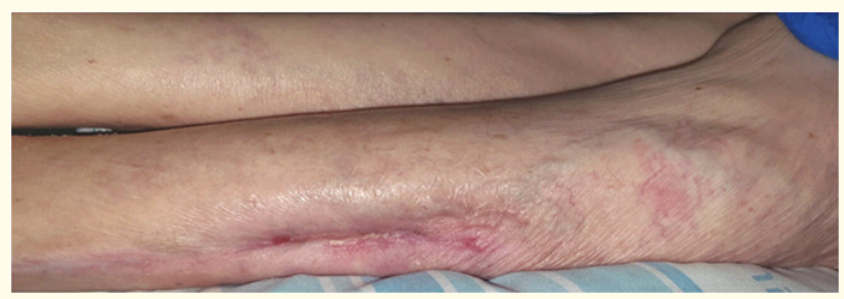

Figure 3: Healed calf pressure ulcer. protein $0.8 \mathrm{mg} / \mathrm{L}$. The patient received oral feeding $32 \mathrm{Kcal} / \mathrm{kg}$ and protein $1 \mathrm{~g} / \mathrm{kg}$ body weight. Her daily medications were olanzapine $15 \mathrm{mg}$, lorazepam $1 \mathrm{mg}$, bisoprolol fumarate $1.25 \mathrm{mg}$, furosemide $40 \mathrm{mg}$, vitamin D $800 \mathrm{U}$ and enoxaparin $40 \mathrm{mg}$ s.c. During an extended stay in our department her general condition was stable. The pressure ulcers were treated with saline gauze dressings changed every 6 hours; their non-inferiority vs. "advanced dressings" being documented $[8,9]$. First to heal were the calf ulcers by December 2018 (Figure 3), followed 2 - 3 months later by the other ulcers. By February 2019 the size of the presacral ulcer had diminished by only 30 percent.

\section{Case 2}

A 48-year-old man suffered a cardiac arrest at home. He was successfully resuscitated. Cardiac catheterization showed patent coronary arteries. Status epilepticus developed and he was transferred to neurology, received anticonvulsive therapy with partial suppression of the spells. He remained in vegetative state, had repeated pulmonary and urinary infections, and pressure ulcers developed during a 3-months hospital stay. When admitted to our department in August 2018 he was emaciated, the body mass index was 18.4 and muscle wasting was severe. There was a presacral pressure ulcer $9 \mathrm{~cm}$ in diameter with direct bone contact. A second pressure ulcer had developed in the vicinity of the right scapula, $4 \mathrm{~cm}$ in diameter, with deep pocketing and direct contact to ribs. A skin ulcer on the right calf, $14 \mathrm{~cm}$ long, $2.5 \mathrm{~cm}$ wide and $3 \mathrm{~mm}$ deep had granulation tissue at the base and a broad rim of new epithelium at the periphery. A skin ulcer on the left calf of similar size was completely epithelized. Among laboratory tests, remarkable were hemoglobin $11.4 \mathrm{~g} / \mathrm{dL}$, albumin $2.6 \mathrm{~g} / \mathrm{dL}, \mathrm{C}$ reactive protein $7.6 \mathrm{mg} / \mathrm{L}$. He received enteral feeding through gastrostomy 35 $\mathrm{Kcal} / \mathrm{kg} /$ day and protein $1.2 \mathrm{~g} / \mathrm{kg} /$ day. The daily doses of medications were phenytoin sodium $200 \mathrm{mg}$, levetiracetam $1500 \mathrm{mg}$, insulin glargine and transcutaneous fentanyl $12.5 \mathrm{mcg} / 72$ hours. The pressure ulcers were treated with saline gauze dressings and the adjacent dermatitis with antifungal crèmes. By February 2019 the calf ulcers were healed while the remaining pressure ulcers had only slightly improved.

\section{Case 3}

A 55-year-old man was transferred to our institution for end-oflife care. Recently he was found in narcotic overdose, deep coma, 
shock, aspiration pneumonia, respiratory and acute renal failure. He was mechanically ventilated and received antibiotic treatment. During prolonged hospitalization he had developed numerous pressure ulcers in the presacral area, the heels, ear and calves. On the posterior aspect of each calf there was a stage elongated skin ulcer: $18 \mathrm{~cm}$ long and $2 \mathrm{~cm}$ wide on the right calf, $13 \mathrm{~cm}$ long and $2 \mathrm{~cm}$ wide on the left calf. The patient did not recover from vegetative state and multiorgan failure. He died shortly after admission.

\section{Case 4}

This 65-year-old man suffering from late onset familial muscular dystrophy had been ambulatory with the use of a walker. At home, he suffered a cardiac arrest. He was resuscitated and rushed to hospital in vegetative state from which he did not recover. He was mechanically ventilated. The hospital course was by complicated by the development of ventilator-associated pneumonia and urinary tract infections. Pressure ulcers emerged in the pre-sacral area, adjacent to the trochanters, scapula, shoulder, scalp, ear and calves (the diameters of the calf ulcers were $12 \times 4 \mathrm{~cm}$ and $7 \mathrm{x}$ $3 \mathrm{~cm}$, respectively). He was mechanically ventilated and received enteral feeding through a nasogastric tube. His daily medications comprised $1000 \mathrm{mg}$ sodium valproate, $75 \mathrm{mg}$ metoprolol and 20 mg esomeprazole. He died 21 days after admission. No changes were apparent in the pressure ulcers during this time.

\section{Case 5}

This 84-year-old man was admitted for rehabilitation after 29day stay in hospital for pneumonia and cardio-respiratory failure. His medical history was notable for hemicolectomy, arterial hypertension and chronic atrial fibrillation. By the time he recently felt he was receiving anticoagulant prophylaxis with dabigatran. On admission a subdural hematoma was diagnosed, the anticoagulant treatment discontinued and intermittent pneumatic compression to the calves was instituted.

He continued treatment with daily phenytoin $200 \mathrm{mg}$, trazodone $50 \mathrm{mg}$, omeprazole $20 \mathrm{mg}$, and vitamin D 800U. After two weeks pneumatic compression was replaced with enoxaparin $40 \mathrm{mg} /$ day. A shallow ulcer had developed on the patient's right calf. The calf ulcer healed 3 weeks later.

\section{Case 6}

A 90 year-old woman, living in the community was hospitalized with aspiration pneumonia and acute respiratory failure. Mechani- cal ventilation was initiated. Her medical history included myocardial infarction, diabetes mellitus, arterial hypertension, atrial fibrillation and venous thromboembolism. During hospitalization she developed ventilator-associated pneumonia, shock and acute renal failure. Anticoagulant treatment was temporarily discontinued and intermittent pneumatic compression was applied to the calves until the renal function improved and heparin sodium was initiated. Following unsuccessful trials of weaning from mechanical ventilation she was transferred to our institution for long-term life support. She was alert and hemodynamically stable. A stage 3 skin ulcer was present on her left calf, $10 \times 4 \mathrm{~cm}$ in diameter, with a rim of new epithelium at the periphery (Figure 4). There were no other skin ulcers. Notable among the laboratory tests were hemoglobin $8.5 \mathrm{~g} / \mathrm{dL}$, serum albumin $2.5 \mathrm{~g} / \mathrm{dL}$ and eGFR $42 \mathrm{~mL} /$ minute. The patient's medications were lercanidipine $20 \mathrm{mg} /$ day, esomeprazole $20 \mathrm{mg} /$ day and heparin sodium. Under treatment with saline gauze dressings the calf ulcer healed.

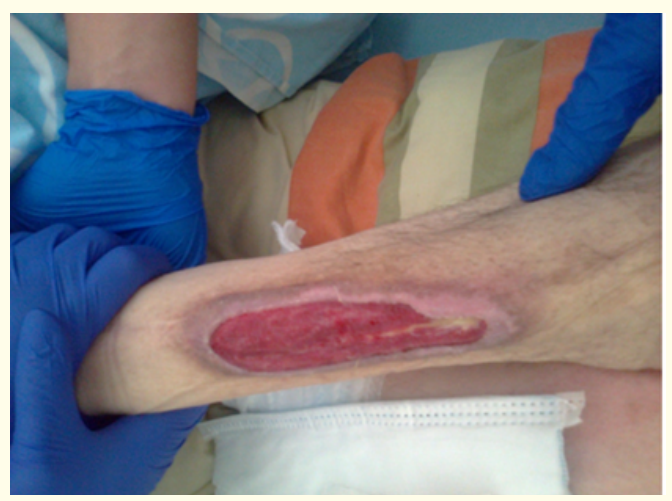

Figure 4: Calf pressure ulcer after injury by intermittent pneumatic compression.

\section{Discussion}

The calf ulcers in the six patients differed from venous, ischemic, neuropathic and stasis ulcers as well as from vasculitic, metabolic, infectious, neoplastic skin ulcers, pyoderma gangrenosum and calciphylaxis $[1,2,5]$. Except for their elongated shape, contrasting to the round shape of pressure ulcers at other sites, the calf ulcers in the six patients were similar to typical pressure ulcers [1,2]. In the six patients the calf ulcers appeared alike the 'typical pressure ulcers' except for their elongated shape. Alike typical pressure ulcers their borders were regular and well demarcated, and the adjacent 
skin appeared normal. Alike typical pressure ulcers, the calf ulcers occurred in hospital during an acute severe illness. In four patients the calf ulcers occurred concurrently with the typical pressure ulcers.

In the patients described as Cases 1 - 4, the pressure ulcers appeared under multisystem deterioration (shock, sepsis, hypoxia, multiorgan failure) along with exposure of the skin to local injury. These four patients developed numerous, bilateral pressure ulcers, both calves involved, in what appeared to be "systemic" pressure injury. The clinical picture may be in extremis that described as "Kennedy Terminal Ulcer", characterized by rapid onset and rapid tissue breakdown [10]. At difference, patients described under Case 5 and Case 6 developing but one calf ulcer and no further pressure injury. The cause of the "locally limited" pressure injury in these two patients appeared to be local, related to the use of intermittent pneumatic compression for thromboprophylaxis. Indeed, skin breaks [11] and rarely pressure ulcers [12] belong to adverse effects of intermittent pneumatic compression. Hence, calf ulcers may be part of systemic pressure injury or the result of locally limited damage.

Underreporting of calf pressure ulcers might be due to the conflict between bedside observation and the ischemic concept of pressure injury. Their development cannot be explained by the classical theory of pressure injury since interface pressures on the calves were thought not reaching the capillary closing pressure of $30-32 \mathrm{mmHg}$. Recently, the pathophysiology of pressure injuries was revised based on MRI and digital fluorescent microscopy studies. Misconceptions were identified [13]. First, under weightbearing and immobility the capillaries in the affected tissues are not completely occluded but stay, at least partially, open [14]. Second, the correlation between interface pressures and internal tissue pressures is weak. Since stage 3 and 4 pressure injuries begin in the deep tissues, the $32 \mathrm{mmHg}$ "ischemia threshold" measured in superficial capillaries might be misleading $[13,15]$. Third, sustained tissue deformation caused by body weight damages the integrity of cells while pressure applied in excess does not necessarily cause ischemia. Cell membrane buckling and rupture alters the transmembrane transport of biomolecules and ions, causes volume changes and alters the cytoskeleton, affecting cellular viability. Apoptosis and cell death may ensue [16]. Ischemia adds to the severity of tissue injury several hours after injury has been caused by tissue deformation $[17,18]$. Fourth, systemic factors might be crucial in modifying tissue tolerance to deformation and ischemia.
Hypotension, blood flow redistribution, damage by proinflammatory cytokines, acidosis and electrolyte disturbances might impact the tissues' tolerance to ischemia. Persistent alterations of the microcirculation despite restoration of macro-hemodynamics and reperfusion injury during removal of pressure load can add to tissue injury [19]. There is no fix value of tissue pressure above which injury develops, rather different levels of tissue pressure can become critical depending on systemic and local influences [20].

External pressure alone might not suffice to cause a pressure injury. Rather, interaction of local forces with systemic alterations lead to tissue damage. Hence, it is not surprising that most pressure ulcers emerge during hospitalization for acute severe illness [2] as a part of the multiorgan system failure.

\section{Conclusion}

Six case histories provide evidence that calf ulcers may be genuine pressure ulcers as part of systemic pressure injury or as a limited local damage. Observations at bedside lend support to the recent, broadened understanding of the pathophysiology of pressure injury.

\section{Funding}

This work did receive funding.

\section{Conflicts of Interest}

None.

\section{Informed Consent}

Patient consent is not required the information being is anonymized images may not identify the person.

\section{Bibliography}

1. Known R., et al. "Pressure ulcers". In: Plastic Surgery: Fourth Edition, Elsevier. 4.16 (2018): 350-380.e83.

2. Edsberg LE., et al. "Revised National Pressure Ulcer Advisory Panel Pressure Injury Staging System: Revised Pressure Injury Staging System". Journal of Wound, Ostomy and Continence Nursing 43 (2016): 585-597.

3. Bader DL and Gant CA. "Changes in transcutaneous oxygen tension as a result of prolonged pressure at the sacrum". Clinical Physics and Physiological Measurement (1988).

4. Clark M., et al. "Measurement of soft tissue thickness over the sacrum of elderly hospital patients using B-mode ultrasound". Decubitus 2 (1989): 63. 
5. Lindan 0., et al. "Pressure distribution on the surface of the human body I. Evaluation in lying and sitting positions using a "bed of springs and nails". Archives of Physical Medicine and Rehabilitation 46 (1965): 378.

6. Hoffman MD. "At risk ulcers'”. Dermatology Theraphy 26 (2013): 222-235.

7. Naschitz J. "Calf pressure ulcers-fact defying the concept". Postgraduate Medical Journal 95 (2019): 565.

8. Westby MJ., et al. "Dressings and topical agents for treating pressure ulcers". Cochrane Database System Review 6 (2017): CD011947.

9. Furuya-Kanamori L., et al. "Effectiveness of different topical treatments in the healing of pressure injuries: A network meta-analysis". Journal of the American Medical Directors Association 20 (2019): 399-407.

10. Bateman J. "Kennedy Terminal Ulcer \#383". Journal of Palliative Medicine 22 (2019): 1612-1613.

11. CLOTS (Clots in Legs Or sTockings after Stroke)., et al. "Effectiveness of intermittent pneumatic compression in reduction of risk of deep vein thrombosis in patients who have had a stroke (CLOTS 3): a multicentre randomised controlled trial". Lancet 382 (2013): 516.

12. Skillman J and Thomas S. "An audit of pressure ulcers caused by intermittent compression devices used to prevent venous thromboembolism". Journal of Perioperative Practice 21 (2011): 418-420.

13. Gefen A., et al. "Clinical and biomechanical perspectives on pressure injury prevention research: The case of prophylactic dressings". Clinical Biomech (Bristol, Avon) 38 (2016): 29-34.

14. Linder-Ganz E and Gefen A. "The effects of pressure and shear on capillary closure in the microstructure of skeletal muscles". Annuals of Biomed Engineering 35.12 (2007): 2095-107.

15. Bogie KM., et al. "New technique for real-time interface pressure analysis: getting more out of large image data sets". Journal of Rehabilitation Research and Development 45 (2008): 523-535.
16. Bader DL and Worsley PR. "Technologies to monitor the health of loaded skin tissues". Biomed Engineering Online 17 (2018): 40.

17. Oomens CW., et al. "Pressure induced deep tissue injury explained". Annuals of Biomed Engineering 43 (2015): 297-305.

18. Gefen A and Weihs D. "Cytoskeleton and plasma-membrane damage resulting from exposure to sustained deformations: A review of the mechanobiology of chronic wounds". Medical Engineering and Physics 38 (2016): 828-833.

19. Peirce SM., et al. "Ischemia-reperfusion injury in chronic pressure ulcer formation: a skin model in the rat". Wound Repair and Regeneration 8 (2000): 68-76.

20. Alvarez OM., et al. "The VCU Pressure Ulcer Summit the search for a clearer understanding and more precise clinical definition of the unavoidable pressure injury". JWOCN 43 (2016): 455-463.

\section{Assets from publication with us}

- Prompt Acknowledgement after receiving the article

- Thorough Double blinded peer review

- Rapid Publication

- Issue of Publication Certificate

- High visibility of your Published work

Website: www.actascientific.com/

Submit Article: www.actascientific.com/submission.php

Email us: editor@actascientific.com

Contact us: +919182824667 